\title{
Somatic and Body Composition Factors Underlying Aerobic Capacity
}

\author{
Sukanta Saha \\ Department of Physical Education, Memari College, Memari, Burdwan, 713146, West Bengal, India
}

Email address:

sahasukanta1980@gmail.com

To cite this article:

Sukanta Saha. Somatic and Body Composition Factors Underlying Aerobic Capacity. American Journal of Sports Science. Vol. 3, No. 2, 2015, pp. 36-40. doi: 10.11648/j.ajss.20150302.12

\begin{abstract}
The purpose of this study was to determine the impact of somatic and body composition variables on aerobic capacity among the male college students. Five hundred (250 trained and 250 untrained) young college levels male students (mean age 20.54 years) participated in this study. In order to evaluate the somatotype components (endomorphy, mesomorphy, ectomorphy) and body composition variables (body mass index, \% body fat, lean body mass, \% skeletal muscle mass, \% skeletal mass and body surface area) researcher applied a testing procedure that included measurements of height $(\mathrm{cm})$, body weight $(\mathrm{kg}$ ), five muscle girths (upper arm, fore arm, chest, thigh and calf) in $\mathrm{cm}$, four bone diameters (humerus, bistyloid, femur and bimalleolus) in cm, and eight skinfolds thickness (triceps, sub-scapular, suprailiac, pectoral, axilla, abdominal, thigh and calf) in $\mathrm{mm}$. Estimation of aerobic capacity through $\dot{V} \mathrm{O}_{2 \max }$. Queen College Step Test was administered. A negative correlation was found between the body fat percentage and $\dot{\mathrm{VO}}_{2 \max }$. Also a negative correlation was found to $\dot{\mathrm{V}} \mathrm{O}_{2 \max }$. with body surface area and endomorphy of both trained and untrained groups. The lean body mass, \% skeletal muscle mass and mesomorphy components of somatotype have the greatest positive correlations with $\dot{\mathrm{V}} \mathrm{O}_{2 \max }$.
\end{abstract}

Keywords: $\dot{\mathrm{V}}_{2 \max }$, Lean Body Mass, \% Body Fat, Somatotype

\section{Introduction}

Aerobic capacity is usually expressed in terms of maximal oxygen uptake $\left(\dot{\mathrm{V}} \mathrm{O}_{2 \text { max. }}\right)$ capacity. Two important factors determinant of $\dot{\mathrm{V}} \mathrm{O}_{2 \max }$ are body composition and somatotype components. Body composition is the substances by which the body frame of an individual made-up and somatotype is the physical classification of the human physique. Measurements of aerobic capacity reveal the quality of number of body systems, particularly muscular, cardiovascular, hematological and the respiratory systems.

The variables that can be used to explain the variance in $\dot{\mathrm{V}} \mathrm{O}_{2 \text { max. }}$ include training status, genetic predisposition, body mass, body composition, maximal arteriovenous oxygen content difference, maximal heart rate, maximal cardiac output, and somatotype components [1]. Previous pertinent studies indicated body mass [2-3], fat free mass [4], \% body fat [5], and body surface area [6], are the best predictor of $\dot{\mathrm{V}} \mathrm{O}_{2 \max }$. The available studies, which primarily consist of $\dot{\mathrm{V}} \mathrm{O}_{2 \text { max. }}$ and lean body mass (LBM) measurements in sedentary subjects, are difficult to interpret due to the confounding effects of age associated changes in body fat and muscle oxidative capacity [7]. Additionally, many studies of the decline in $\dot{\mathrm{V}} \mathrm{O}_{2 \text { max. }}$ with aging, particularly in trained subjects, have not statistically adjusted $\dot{\mathrm{V}} \mathrm{O}_{2 \max }$ for age or gender differences in body composition [8]. Finally, it is unclear what relevance indicators of whole body muscle mass have as determinants of $\dot{\mathrm{V}} \mathrm{O}_{2 \text { max. }}$ when most of the $\mathrm{O}_{2}$ consumed during $\mathrm{V}_{2 \text { max. }}$ testing is used by the limb muscles [9].

It is well known that absolute $\dot{\mathrm{V}} \mathrm{O}_{2 \max }$ is strongly influenced by change in body size. For that reason body size should help to explain the aerobic capacity of an individual [10]. Some recent studies have shown that there are separate and independent health effects of aerobic capacity and fatness [11]. It has recently been argued that aerobic capacity is the primary factor influencing future health outcome [12], although the physiological basis of this concept remains unclear. The purpose of this study was to examine the influence of body composition variables and somatotype components on aerobic capacity. 


\section{Material and Methods}

\subsection{Subjects}

The present study was conducted on 250 trained and 250 untrained (total 500) young college levels male students (age range 18-25 years). Trained students were completed one year Bachelor of Physical Education (B.P.Ed) course and took part in obligatory physical activities under their course of study and untrained students were not participated regular physical activity. The subjects were selected from nineteen colleges located in nine different districts of West-Bengal in India irrespective of their caste, religion, dietary habits and socio-economic status. The age of the subjects were calculated from the date of birth as recorded in their institution. The investigation received ethical approval from the Visva Bharati University Research Degrees Ethics Committee.

\subsection{Anthropometric Measurements}

The anthropometric measurements were carried out using standard instruments and in accordance with the methodology recommended by the International Society for the Advancement of Kinanthropometry [13]. Body height was evaluated in $\mathrm{cm}$, along with body weight in $\mathrm{kg}$, five muscle girths (upper arm, fore arm, chest, thigh and calf) in $\mathrm{cm}$, four bone diameters (humerus, bistyloid, femur and bimalleolus) in $\mathrm{cm}$, and eight skinfolds thickness (triceps, sub-scapular, suprailiac, pectoral, axilla, abdominal, thigh and calf) in $\mathrm{mm}$.

\subsection{Body Composition and Somatotype}

For calculating body density of the subjects Jackson and Pollock [14] formula was adopted. The Siri Equation [15] was used to convert body density to percent body fat of each participant. Poortman's [16] and Drinkwater et al. [17] formula was taken up for assessing skeletal muscle mass and skeletal mass respectively. Measurement of body surface area (BSA) of the subjects Mosteller's Formula [18] was used. Somatotype components (endomorphy, mesomorphy and ectomorphy) of the subjects were calculated according to Carter and Heath anthropometric method [19].

\subsection{Aerobic Capacity}

Estimation of aerobic capacity through $\dot{\mathrm{V}}_{2 \text { max. }}$ by Queen College Step Test [20] was administered. Subjects were performed stepping exercise using a bench of 16.25 inches height. Stepping was done for total duration of 3 minutes at the rate of 24 steps up/minute, which was set by a metronome. After completion of exercise subjects were allowed to remain standing comfortably and carotid pulse rate was measured from $5^{\text {th }}$ to $20^{\text {th }}$ seconds of recovery period. This 15 seconds pulse rate multiplied by 4 to give per minute pulse count and the following equation used to predict $\dot{\mathrm{V}} \mathrm{O}_{2 \max }$. The $\dot{\mathrm{V}} \mathrm{O}_{2 \max }$. $\left(\mathrm{ml} . \mathrm{kg}^{-1} \mathrm{~min}^{-1}\right)=111.33-(0.42 \times$ pulse rate in beats $/ \mathrm{min})$.

\section{Results}

Table 1. Body composition variables of trained and untrained students.

\begin{tabular}{|c|c|c|c|c|c|}
\hline \multirow{2}{*}{ Variables } & \multicolumn{2}{|c|}{ Trained } & \multicolumn{3}{|c|}{ Untrained } \\
\hline & Mean & S.D. & Mean & S.D. & t-Value \\
\hline Weight (kg) & 60.44 & 5.53 & 58.43 & 6.48 & $3.71 * *$ \\
\hline Height $(\mathrm{cm})$ & 168.33 & 5.59 & 168.82 & 5.63 & 0.97 \\
\hline BMI & 21.31 & 1.35 & 20.51 & 2.06 & $5.11 * *$ \\
\hline$\%$ Fat & 12.37 & 3.01 & 14.36 & 3.69 & $6.58 * *$ \\
\hline Lean Body Mass & 52.9 & 4.55 & 49.95 & 5.23 & $6.70 * *$ \\
\hline$\%$ Skeletal Mass & 13.57 & 1.34 & 13.38 & 0.98 & 1.80 \\
\hline$\%$ Skeletal Muscle Mass & 49.79 & 3.22 & 48.35 & 3.32 & $4.90 * *$ \\
\hline Body Surface Area $\left(\mathrm{m}^{2}\right)$ & 1.68 & 0.09 & 1.65 & 0.10 & $3.51 * *$ \\
\hline
\end{tabular}

$* *$ indicates $\mathrm{p}<0.01$

Table 2. Somatotype components of trained and untrained students.

\begin{tabular}{llllll}
\hline \multirow{2}{*}{ Variables } & \multicolumn{2}{l}{ Trained } & \multicolumn{5}{c}{ Untrained } \\
\cline { 2 - 6 } & Mean & S.D. & Mean & S.D. & t-Value \\
\hline Endomorphy & 3.85 & 0.86 & 4.37 & 1.01 & $6.17^{* *}$ \\
Mesomorphy & 4.67 & 0.88 & 4.14 & 1.23 & $5.51^{* *}$ \\
Ectomorphy & 2.86 & 0.74 & 3.34 & 1.18 & $5.42^{* *}$ \\
\hline
\end{tabular}

$* *$ indicates $\mathrm{p}<0.01$

Table 3. Aerobic capacity of trained and untrained students.

\begin{tabular}{llllll}
\hline \multirow{2}{*}{ Variables } & \multicolumn{3}{c}{ Trained } & \multicolumn{4}{c}{ Untrained } \\
\cline { 2 - 6 } & Mean & S.D. & Mean & S.D. & t-Value \\
\hline$\dot{\mathrm{V} O}{ }_{2 \text { max. }}\left(\mathrm{ml.kg.}^{-1} \mathrm{~min}^{-1}\right)$ & 54.83 & 5.38 & 40.91 & 6.51 & $36.78^{* *}$ \\
\hline$* *$ indicates $\mathrm{p}<0.01$ & & & & &
\end{tabular}

Table 4. Pearson correlation of body composition and somatotype with aerobic capacity.

\begin{tabular}{lll}
\hline \multirow{2}{*}{ Variables } & \multicolumn{2}{l}{$\dot{\text { VO}}_{2 \text { max. }}\left(\mathrm{ml.kg}^{-1} \mathbf{m i n}^{-1}\right)$} \\
\cline { 2 - 3 } & Trained & Untrained \\
\hline Weight $(\mathrm{kg})$ & $0.657^{* *}$ & $0.476^{* *}$ \\
Height $(\mathrm{cm})$ & $0.466^{* *}$ & $0.385^{* *}$ \\
BMI & $0.338^{* *}$ & $0.137 *$ \\
\% Body Fat & $-0.344^{* *}$ & $-0.516^{* *}$ \\
\% Skeletal Muscle Mass & $0.364 * *$ & $0.297 * *$ \\
\% Skeletal Mass & 0.068 & 0.056 \\
Lean Body Mass $(\mathrm{Kg})$ & $0.763 * *$ & $0.539 * *$ \\
Body Surface Area $\left(\mathrm{m}^{2}\right)$ & $-0.135^{*}$ & $-0.124 *$ \\
Endomorphy & $-0.361 * *$ & $-0.519 * *$ \\
Mesomorphy & $0.684 * *$ & $0.455^{* *}$ \\
Ectomorphy & $0.418^{* *}$ & $0.186^{* *}$ \\
\hline
\end{tabular}

$* *$ indicates $\mathrm{p}<0.01$ and $*$ indicates $\mathrm{p}<0.05$

Body composition variables and somatotype components of trained and untrained college students were shown in table $1 \& 2$ respectively. The trained subjects had significantly greater value of body mass index $(\mathrm{p}<0.01)$ as compared to untrained students. Lean body mass $(p<0.01), \%$ skeletal muscle mass $(\mathrm{p}<0.01)$ and body surface area $(\mathrm{p}<0.01)$ were found significantly higher in trained students when compared to the untrained students. Trained college students also had significantly high mesomorphic score $(p<0.01)$ when compared to untrained students; whereas, endomorphy $(\mathrm{p}<0.01)$ and ectomorphy $(\mathrm{p}<0.01)$ score of the untrained students were significantly greater than trained students. No significant difference was reported between the two groups in relation to $\%$ skeletal mass. Table 3 presents the $\dot{\mathrm{V}} \mathrm{O}_{2 \max }$ of 
trained and untrained students. The trained students had significantly higher amount of $\dot{\mathrm{V}} \mathrm{O}_{2 \max } .(\mathrm{p}<0.01)$ than the untrained students.

Table 4 comprises the coefficients of correlation for both trained and untrained groups of $\dot{\mathrm{V}} \mathrm{O}_{2 \max }$. with various body composition variables and somatotype components. Significant positive correlation $(\mathrm{p}<0.01)$ was observed in both group when maximum oxygen uptake capacity was correlated with BMI, \% skeletal muscle mass, lean body mass, mesomorphy and ectomorphy component; whereas, negatively correlated with $\%$ body fat $(\mathrm{p}<0.01)$, body surface area $(p<0.05)$ and endomorphy component $(p<0.01)$. In Figure 1 it can be observed the $\dot{\mathrm{V}} \mathrm{O}_{2 \text { max. }}$ values of the trained (higher) and untrained students (lower) in respect to somatotype components. Comparison of $\dot{\mathrm{V}}_{2 \max }$ of trained and untrained students in reverence to \% body fat and lean body mass was presented in Figure 2.
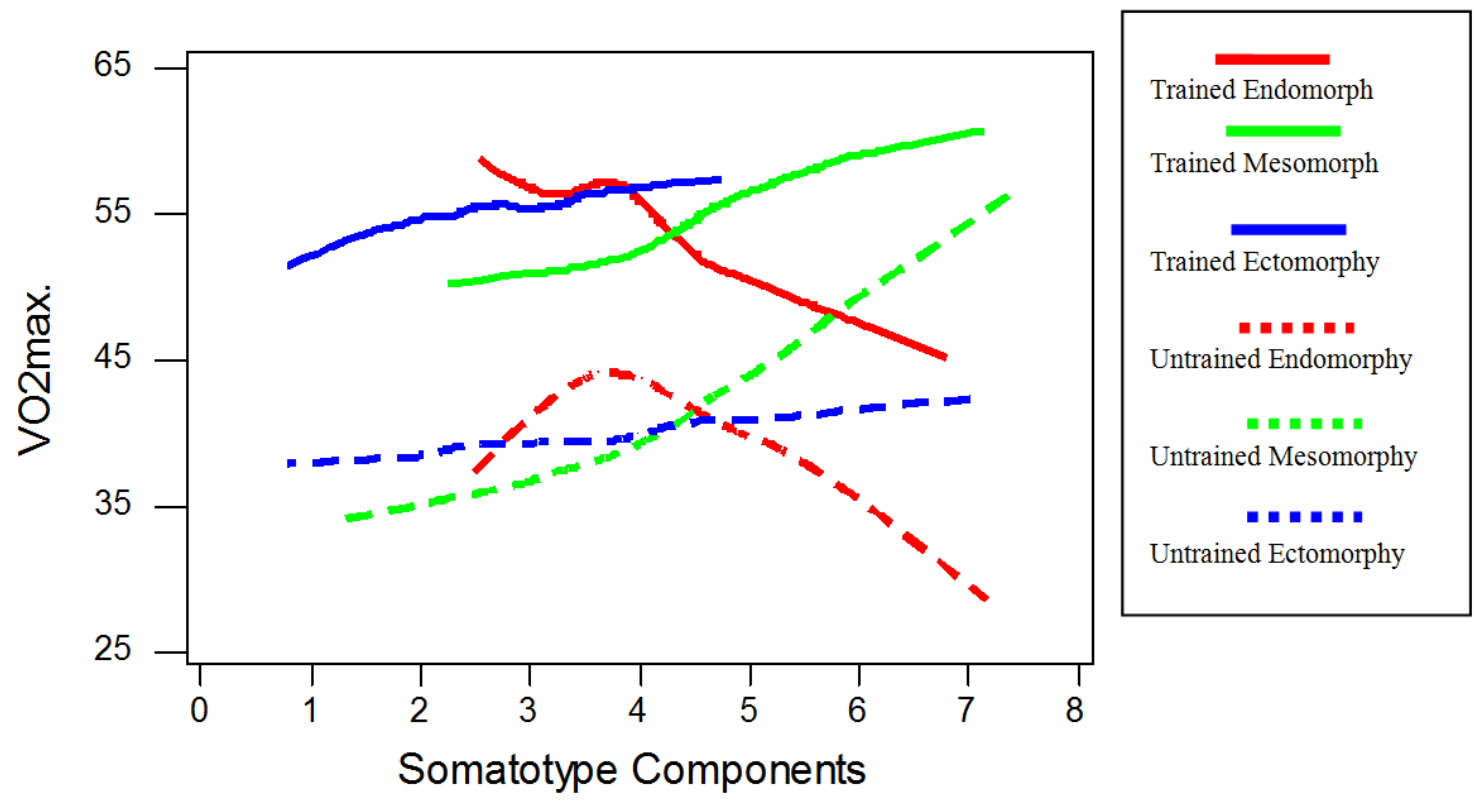

Figure 1. Comparison of $\dot{V} O_{2 \max }$ of trained and untrained students in relation to somatotype components.
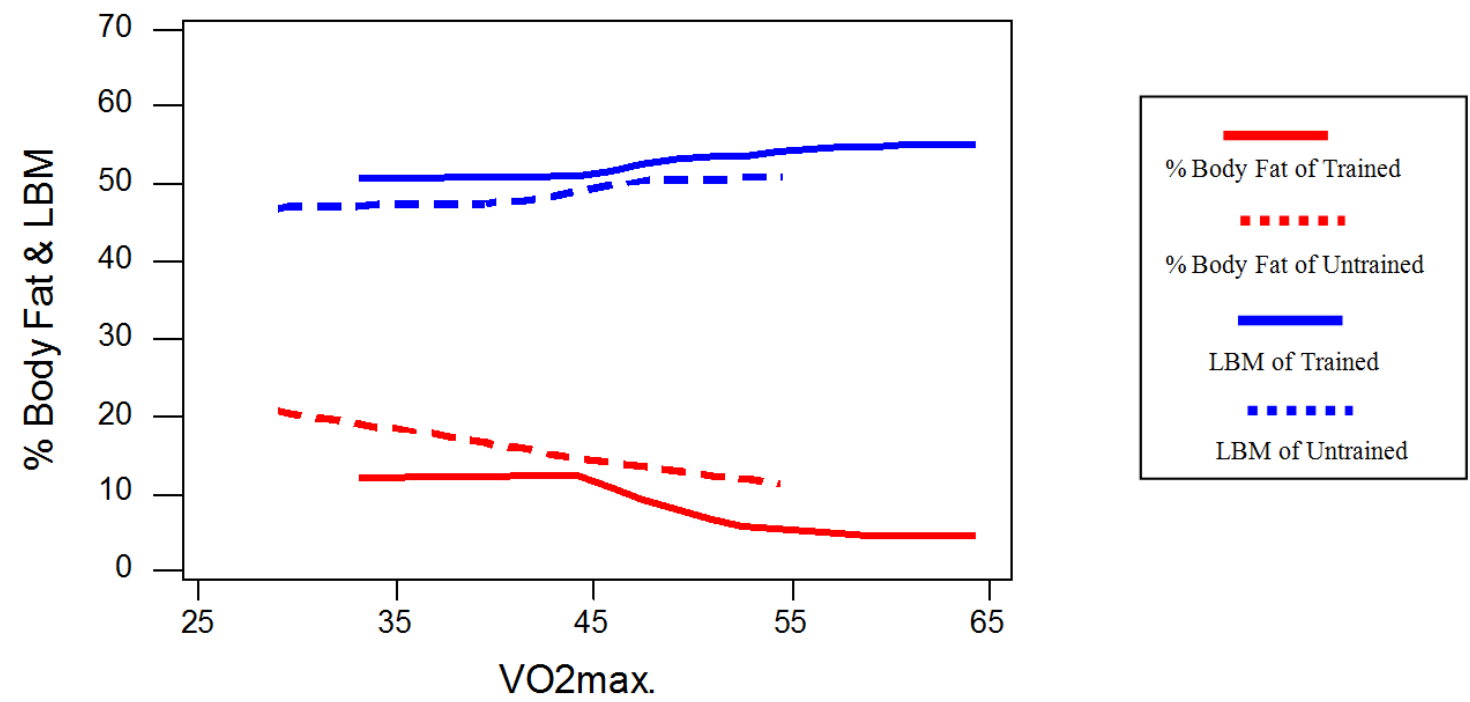

Figure 2. Comparison of $\dot{V} O_{2 \max }$ of trained and untrained students in relation to \% body fat and lean body mass (LBM).

\section{Discussion}

Previous pertinent studies indicated body mass as the best predictor of $\dot{\mathrm{V}} \mathrm{O}_{2 \max }$. [2-3,6,21]. In the present study body mass exhibited higher value of correlation coefficient $(\mathrm{r}=0.657)$ with $\dot{\mathrm{V}} \mathrm{O}_{2 \max }$. than height $(\mathrm{r}=0.466)$ in case of trained students, while untrained students depicted lower value of correlation coefficient $(\mathrm{r}=0.476)$ between body mass and $\dot{\mathrm{V}} \mathrm{O}_{2 \text { max. }}$ than that of between height and $\dot{\mathrm{V}} \mathrm{O}_{2 \max .}(\mathrm{r}=0.385)$. Verma et al. [21] in their studies proposed that physical characteristics are good predictors of maximal oxygen uptake in Indian males and more importantly they obtained highest value of correlation coefficient when body mass was considered as an independent parameter.

In accordance with the results published by Sporis et al. 
[22] and Saha S. [23] present study also established negative correlation to body fat percentage with $\dot{\mathrm{V}} \mathrm{O}_{2 \text { max. }}$ This is probably because of the excessive amount of body fat that appeared to exert an unfavorable burden as well as hindering action towards cardiac function, particularly during exhausting exercise when excessive hyperactive body musculature fails to uptake sufficient amount of oxygen due to deposition of proportionately high amount of fat mass [4]. Similarly, Dempsy et al. [24] found excess body fat impairs cardiorespiratory functions and reduces mechanical efficiency for a given work load. Finding of the present study is in accordance with the work of Lang et al. [25] who described a significant relationship between skeletal muscle mass and $\dot{\mathrm{V}} \mathrm{O}_{2 \max }$. Other author [26] found a significant relationship between $\dot{\mathrm{V}} \mathrm{O}_{2 \text { max. }}$ and thigh muscle cross-sectional area. Therefore, it may be concluded that skeletal muscle mass is an important variable for determining $\dot{\mathrm{V}} \mathrm{O}_{2 \max }$ of an individual. Lean body mass had highly significant correlation with $\mathrm{V}_{2 \text { max. }}$ in both trained and untrained group [7]. These findings provide additional support for expressing dependence of $\dot{\mathrm{V}} \mathrm{O}_{2 \max }$ to lean body mass.

The mesomorph somatotype in both trained and untrained group had highest correlations with $\dot{\mathrm{V}} \mathrm{O}_{2 \max }$. which were expected due to the fact that larger quantity of muscle mass they possessed. The ectomorph somatotype had lower correlations with $\dot{\mathrm{V}} \mathrm{O}_{2 \text { max }}$ than the mesomorph somatotype. As expected that the endomorph somatotype in both group had the negative correlation with $\mathrm{VO}_{2 \text { max. }}$ because endomorphy is related to body fat which has negative impact on aerobic capacity. In this study researcher found a negative correlation between body fat percentages and $\mathrm{VO}_{2 \max }$ as it was the case in prior study [22-23].

\section{Conclusions}

All the body composition and somatotype components were well correlated with $\dot{\mathrm{V}}_{2 \text { max }}$ indicating dependence of the later on somatic and body composition variables. However this study has several limitations: Firstly, all the parameters were determent by predictive equation and the second, sample of participant was not random.

\section{References}

[1] BERGH UB, EKBLOM B, ASTRAND PO. Maximal oxygen uptake classical versus contemporary viewpoints. Med Sci Sports Exerc. 2000; 32:85-88.

[2] BANDYOPADHYAY A, CHATTERJEE S. Body composition, morphological characteristics and their relationship with cardiorespiratory fitness. Ergonomics SA. 2003; 15: 19-27.

[3] BISWAS R, SAMANTA A, CHATTERJEE S. Maximal aerobic capacity of Indian inland fishermen. Indian J Physiol\& Allied Sci. 2004; 58: 70-79.

[4] BUSKIRK E, TAYLOR HL. Maximal oxygen intake and its relation to body composition with special reference to chronic physical activity and obesity. J Appl Physiol. 1957; 11: 72-78.
[5] KAYAR SR, HOPPELER H, JONES JH, LONGWORTH K, ARMSTRONG RB, LAUGHLIN MH, LINDSTEDT SL, BICUDO JE, GROEBE K, TAYLOR CR, WEIBEL ER. Capillary blood transit time in muscles in relation to body size and aerobic capacity. J. expt. Biol. 1994; 194: 69-81.

[6] CHATTERJEE S, CHATTERJEE P, BANDYOPADHYAY A. Prediction of maximal oxygen consumption from body mass, height and body surface area in young sedentary subjects. Indian J Physiol Pharmacol. 2006; 50(2): 181-186.

[7] DAVIES MG, DALSKY G, VANDERBURGH P. Allometric scaling of $\dot{\mathrm{V}} \mathrm{O}_{2 \text { max }}$ by body mass and lean body mass in older men. J. Aging Phys. Act. 1995; 3: 324-331.

[8] TOTH MJ, GORAN MI, ADES PA, HOWARD DB, POEHLMAN ET. Examination of data normalization procedures for expressing peak $\mathrm{V}_{2}$ data. J. Appl. Physiol. 1993; 75: 2288-2292.

[9] KNIGHT DR, POOLE DC, SCHAFFARTZIK W, GUY HJ, PREDILETTO R, HOGAN MC, WAGNER PD. Relationship between body and leg $\dot{\mathrm{V}} \mathrm{O}_{2 \text { max. }}$ during maximal cycle ergometer J. Appl. Physiol. 1992; 73: 1114-1121.

[10] LOFTIN M, SOTHERN M, TROSCLAIR L, O'HANLON A, MILLER J, UDALL J. Scaling $\mathrm{VO}_{2}$ peak in obese and nonobese girls. Obes Res. 2001; 9: 290-296.

[11] LEE CD, BLAIR SN, JACKSON AS. Cardiorespiratory fitness, body composition, and cardiovascular disease mortality in men. Am J Clin Nutr. 1999; 69: 373-380.

[12] LEE CD, JACKSON AS, BLAIR SN. US weight guidelines: Is it also important to consider cardiorespiratory fitness? Int $\mathrm{J}$ Obes. 1998; 22: 52-57.

[13] ROSS WD, MARFELL-JONES MJ. Kinanthropometry. London: Human Kinetics, 1991.

[14] JACKSON AS, POLLOCK ML. Generalized equations for prediction body density of men. Br. J. Nutr. 1978; 40: 497-504

[15] SIRI WE. Gross Composition of the Body. In: Advances in Biological and Medical Physics (Vol. IV). Lawrence, JH, and Tobias, CA, eds. New York: Academic Press, 1956.

[16] POORTMANS JR, BOISSEAU N, MORAINE JJ, MORENOREYES R, GOLDMAN S. Estimation of total body skeletal muscle mass in children and adolescents. Med. Sci. Sports Exerc.2005; 37(2): 316-322.

[17] DRINKWATER BL, NILSON K, CHESNUT CH, BREMNER WJ, SHAINHOLTZ S, SOUTHWORTH MB. Bone Mineral Content of Amenorrheic and Eumenorrheic Athletes. N Engl J Med. 1984; 311: 277-281.

[18] MOSTELLER RD. Simplified calculation of body surface area. N Eng J Med. 1987; 317: 1098.

[19] CARTER L, HEATH B. Somatotyping- Development and applications. Cambridge: University Press, New York, 1990.

[20] McARDLE WD, KATCH IF, KATCH LV. Exercise Physiology: Energy, Nutrition and Human Performance; 5th Ed. 2001.

[21] VERMA SS, SHARMA YK, KISHORE N. Prediction of maximal aerobic power in healthy Indian males 21-58 years of age. Z Morphol Anthropol. 1998; 82: 103-110. 
[22] SPORIS G, JUKIC I, BOK D, VULETA DJR, HARASIN D. Impact of body composition on performance in fitness tests among personnel of the Croatian navy. Coll Antropol. 2011; 35(2): $335-9$.

[23] SAHA S. A new non-exercise based $\dot{\mathrm{V}} \mathrm{O}_{2 \max }$ prediction equation for college students. IJHPECSS. 2013; 9(1): 29-32.

[24] DEMPSY JA, REDDON W, BALKE B, RANKIN J. Work capacity determinants and physiologic cost of weight supported work in obesity. J Appl Physiol. 1966; 21: 18151820.

[25] LANG CC, CHOMSKY DB, RAYOS G. Skeletal muscle mass and exercise performance in stable ambulatory patients with heart failure. J Appl Physiol. 1997; 82: 257-61.

[26] VOLTERRANI M, CLARK AL, LUDMAN PF. Predictors of exercise capacity in chronic heart failure. Eur Heart J. 1994; 15: 801-9. 